\title{
Congress pushes plan to make papers free
}

A question to holders of grants from the National Institutes of Health (NIH): do you plan to submit publications resulting from $\mathrm{NIH}$-funded research to PubMed Central? The answer is probably 'no'. Fewer than $4 \%$ of NIHfunded researchers send their papers to the free-to-access archive, despite the agency having requested that they do so since May 2005.

That could be about to change. The archive is at the heart of plans, backed by a coalition of US politicians and advocacy groups, to make the fruits of publicly funded research freely available. On 13 June, a change was introduced to a House of Representatives spending bill such that $\mathrm{NIH}$ grantees would be required, not requested, to submit to PubMed within 12 months of publication. The proposal has upset some publishers and scientific societies, who are wary of citation confusion and a possible drop in income.

The move is in part a response to the limited impact of NIH's current policy on open access. "It is not working in its current state," says Norka
Ruiz Bravo, NIH deputy director for extramural research and an advocate of full participation in open-access publishing by all grantees.

A majority of the NIH Public Access Working Group, an advisory body that includes publishers and researchers, have also endorsed mandatory submission to PubMed Central, says Thomas Detre, a psychiatrist at the University of Pittsburgh in Pennsylvania and chair of the working group: "Nobody in academia will do anything administrative that's not obligatory."

But critics charge that such a policy could affect the integrity of the scientific literature. Some journals do not allow copyedited versions to be posted on PubMed Central. This means two versions of the same research paper can be published: a peer-reviewed manuscript version held in PubMed Central and a journal version complete with copyedits and other mostly cosmetic modifications. The PubMed Central ver- sion would also not necessarily link to the journal that published the paper. This would unfairly divert web traffic from the journal, and the multiple versions could confuse citation analyses, says Martin Frank, executive director of the American Physiological Societyin Bethesda, Maryland.

Such arguments could be addressed when the Senate drafts its appropriations bill, as some senators are likely to want to include a clause on mandatory submission. In May, for example, Joseph Lieberman and John Cornyn introduced a bill that would require that all federal US agency grantees with annual research budgets of more than $\$ 100$ million make their research papers freely available within six months of publication (Nature 441, 140; 2006).

The Senate's spending bill could be introduced in July, although completion by the autumn is more likely.

Gene Russo

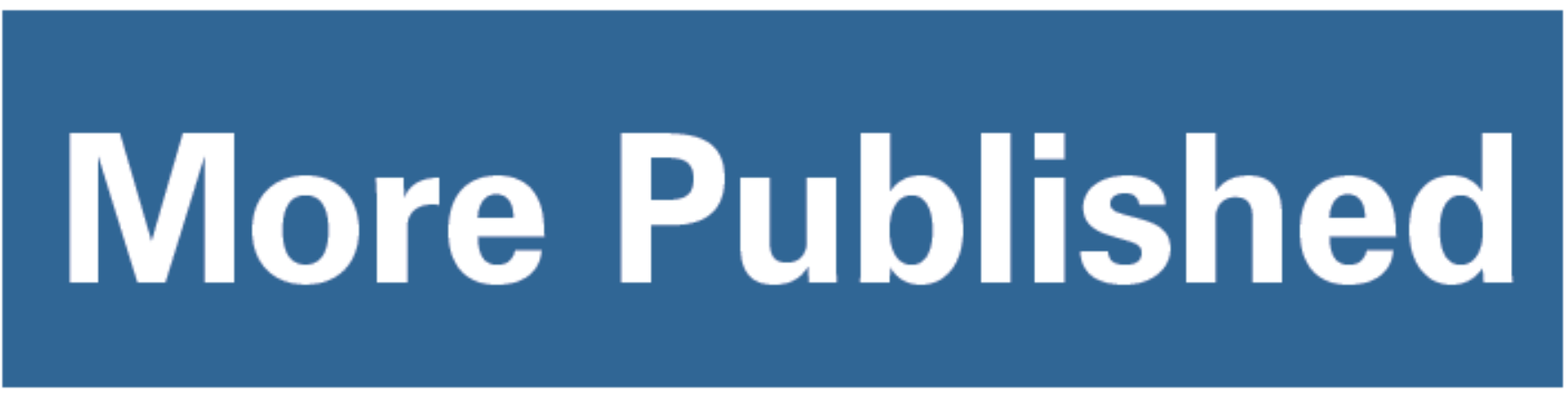

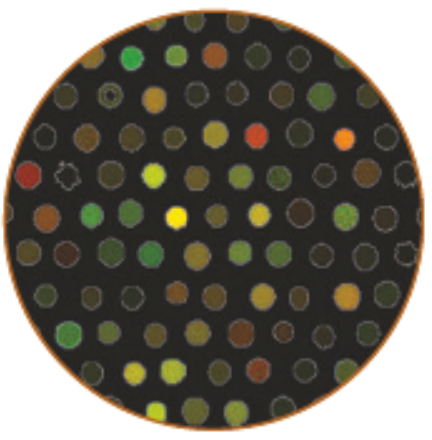

Molecular Devices
In a recent PubMed survey, more publications referenced GenePix * from Molecular Devices than any other slide-based microarray scanner platform. Why? Because researchers trust the results they get with GenePix scanners and Acuity* analysis software. When you trust the tools you use, you have the confidence to publish your results.

Obtaining reliable data requires high performance instruments and software that are easy to use and increase your productivity. With Molecular Devices' microarray

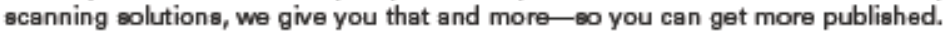

Microarray Scanning

$\odot$ GenePix Autoloader 4200AL: 36-slide capacity with automation

$\ominus$ GenePix Professional 4200A: four-laser flexibility and upgradability

() GenePix 4000B: fastest two-laser scanner in existence

() GenePix Personal 4100A: affordable, quality two-laser scanning

Microarray Analysis Soltware

$\Theta$ GenePix Pro 6 microarray image analysis software

$\odot$ Acuity 4 microarray informatics software

Expect more. We'll do our very best to exceed your expectations. 